\title{
The Place of Nipple-Sparing Mastectomy in the Treatment of Breast Cancer: Review of the Literature
}

\author{
Abdallah El Farouqi*, Anas Boumzough \\ Department of Obstetrics and Gynecology, Agadir Faculty of Medicine and Pharmacy, UHC Agadir, Morocco \\ Email: *elfarouqi.fmpa@gmail.com
}

How to cite this paper: El Farouqi, A. and Boumzough, A. (2021) The Place of Nipple-Sparing Mastectomy in the Treatment of Breast Cancer: Review of the Literature. Open Journal of Obstetrics and Gynecology, 11, 1752-1769.

https://doi.org/10.4236/ojog.2021.1112164

Received: November 3, 2021

Accepted: December 20, 2021

Published: December 23, 2021

Copyright ( 2021 by author(s) and Scientific Research Publishing Inc. This work is licensed under the Creative Commons Attribution International License (CC BY 4.0).

http://creativecommons.org/licenses/by/4.0/

\begin{abstract}
Introduction: Mastectomy with conservation of the nipple-areola complex (NAC) in breast cancer care has been controversial with regards to the oncological safety of this procedure and the risk of complications including NAC necrosis. Aim: The objective of this study is to assess, through a literature review, the safety and reliability of a conservative NAC mastectomy in breast cancer treatment, paying attention to the rate of local recurrence and complications. Methods: A review of the literature was conducted from PubMed data, and articles published between January 2007 and December 2017, using the terms "nipple-sparing mastectomy", "breast cancer", "local recurrence", "necrosis of the nipple", "global complications". The articles were analyzed with regards to the following parameters of evaluation: local recurrence, recurrence rate at NAC level, global complication rates and nipple necrosis rates. Results: In the 36 studies we selected, the average rate of local recurrence was $3.23 \%$. The average rate of recurrence at the NAC was $0.81 \%$. The average rate of complications was $20 \%$. The average rate of necrosis of the NAC was $5.9 \%$. The main factors of these recurrences were the tumor size $>5 \mathrm{~cm}$ and tumor stage $>$ stage II. Conclusion: Conservative mastectomy of the nipple-areola complex offers an aesthetic advantage and oncological safety in carefully selected patients with breast cancer.
\end{abstract}

\section{Keywords}

Nipple-Sparing Mastectomy, Breast Cancer, Local Recurrence, Necrosis of the Nipple, Global Complications

\section{Introduction}

The conservative treatment is the main procedure in the treatment of the major- 
ity of breast cancers. However, a third of patients with breast cancer still need a mastectomy [1] [2].

The reconstruction of the nipple-areola complex (NAC) is crucial to the aesthetic result, but the reconstructed NAC remains problematic: lack of projection, the difference in color, shape, size, texture and relative position to the breast.

Preservation of the NAC will improve the aesthetic outcome and also patient satisfaction by reducing feelings of mutilation and the psychological impact of a mastectomy [3] [4].

In 1962, Freeman [5] described mastectomy with preservation of the NAC. Since 2000, this technique has been increasingly practiced, but was initially reserved for prophylactic mastectomies.

The extent of the indications of breast cancer has raised controversy for the oncological safety of this procedure [6] [7] and the risk of complications including NAC necrosis [8].

If the mastectomy takes place with preservation of the NAC (nipple-sparing mastectomy), often the dissection plane is not clearly defined between the dermis and subcutaneous fat and therefore part of the glandular tissue is left in place [9].

The residual breast parenchyma may have potential for a local recurrence of breast cancer in the short term and long term [10] [11] [12].

The NAC may also be the site of occult residual disease after mastectomy with NAC preservation [13].

Several authors have tried to identify the clinical and pathological risk factors associated with the NAC affected. However, the data are contradictory and often based on studies with small numbers of procedures [14] [15].

The objective of this current study is to assess, through a review of the literature, the safety and reliability of a nipple-sparing mastectomy in breast cancer treatment, paying attention to the rate of local recurrences and complications.

\section{Methods}

We conducted a literature review from PubMed data, and articles published between January 2007 and December 2017, using the terms "nipple-sparing mastectomy", "breast cancer", "local recurrence", "necrosis of the nipple", "global complications" (Figure 1).

\subsection{Selection Criteria}

- Studies had clearly defined patients who underwent mastectomies for breast cancer with preservation of the NAC, the results of this cohort should be indicated separately.

- Indications for breast cancer: Carcinoma in situ or invasive carcinoma.

- All types of reconstructions were included.

- All studies excluded clinical or histological invasion of the NAC. 


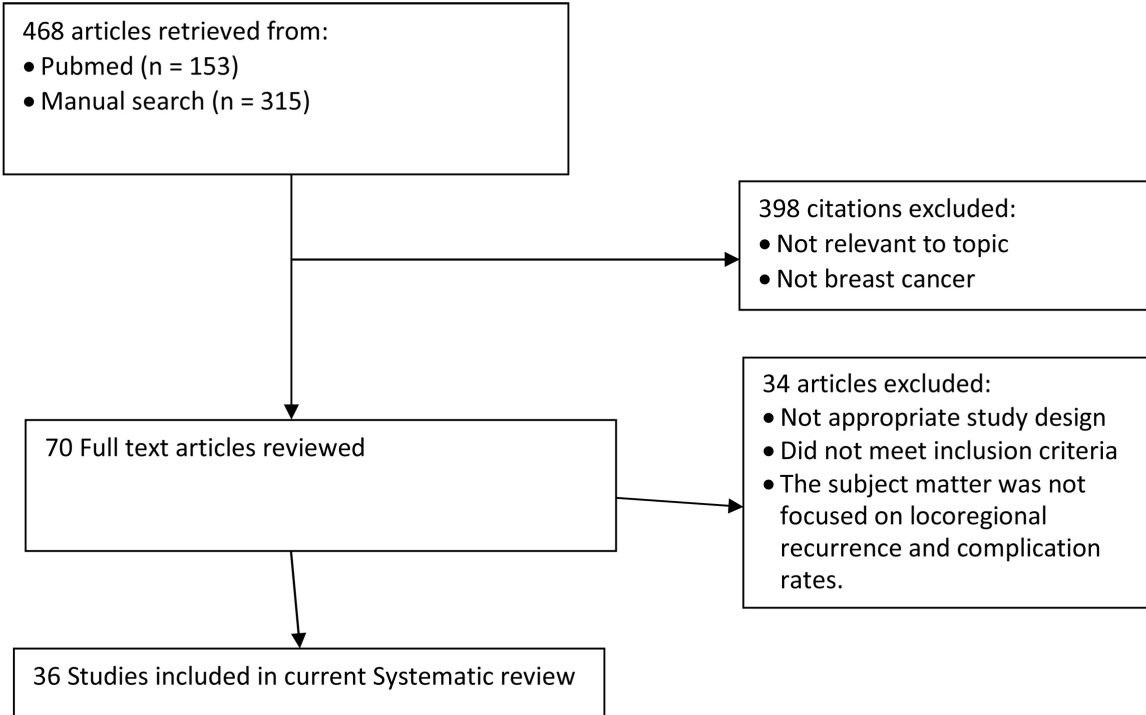

Figure 1. Flowchart outlining literature selection process.

\subsection{Data Retrieved from the Articles}

The author, year of publication, the number of nipple-sparing mastectomy procedures for breast cancer, the mean age of patients, the stage of the tumor, the tumor size, the histologic tumor type, the lymph node involvement, the average follow-up, the type of reconstruction, radiotherapy linked to treatment rates.

The evaluation parameters: local recurrence, recurrence rate at the NAC level, overall complications and nipple necrosis rates.

We then defined 3 subgroups of studies:

- Study Group including stages of tumor.

- Study Group including the rate of patients who underwent radiotherapy.

- Study Group including the types of reconstruction.

Statistical analysis was performed with SPSS Version 20 software, the Pearson correlation test was used to assess correlations between the different impacts: recurrence rate, complication rate and necrosis over settings; follow-up period, the stage of the tumor, linked therapy, the type of reconstruction. Comparisons between groups were made with the Student support test for unpaired series. Differences were considered significant at $\mathrm{P}<0.05$.

\section{Results}

Publications on the place of a nipple-sparing mastectomy in breast cancer treatment are numerous. We selected 36 studies, including 29 retrospective studies and 7 prospective studies. The results and the main characteristics of these studies are listed in Table 1 and Table 2.

The number of nipple-sparing mastectomies for breast cancer treatment ranged from 30 to 1001 with a total of 8618 . Indications included invasive cancer and carcinoma in situ.

The age range varied from 41 to 53 years old with an average patient age of 
Table 1. Study characteristics with local recurrence, recurrence at the NAC, global complications and necrosis of the NAC.

\begin{tabular}{|c|c|c|c|c|c|c|c|c|c|}
\hline Authors & Year & $\begin{array}{l}\text { Type } \\
\text { study }\end{array}$ & NSM & $\begin{array}{l}\text { Mean } \\
\text { Age } \\
\text { year }\end{array}$ & $\begin{array}{c}\text { Average } \\
\text { monitoring } \\
\text { month }\end{array}$ & LR \% & $\begin{array}{c}\text { R.NAC } \\
\%\end{array}$ & $\begin{array}{c}\text { overall } \\
\text { complication } \\
\%\end{array}$ & $\begin{array}{c}\text { NECROSIS } \\
\text { NAC } \\
\%\end{array}$ \\
\hline Denewer [16] & 2007 & $\mathrm{R}$ & 41 & 42 & 8 & 0 & 0 & 26.4 & 2.4 \\
\hline Benediktsson [17] & 2008 & $\mathrm{P}$ & 202 & 53 & 156 & 24 & 4 & - & 8 \\
\hline Crowe [18] & 2008 & $\mathrm{P}$ & 61 & 43 & 41 & 3 & 0 & - & 1.5 \\
\hline Regulus [19] & 2008 & $\mathrm{R}$ & 84 & 42 & 16 & 0 & 0 & - & 0 \\
\hline Voltura [20] & 2008 & $\mathrm{R}$ & 34 & - & 18 & 5.9 & 0 & - & - \\
\hline Wijayanayagan [21] & 2008 & $\mathrm{P}$ & 35 & 44 & - & 0 & 6.9 & 42 & 5 \\
\hline Garwood [22] & 2009 & $\mathrm{P}$ & 99 & - & 13 & 0.6 & 0 & - & 10.4 \\
\hline Gerber [23] & 2009 & $\mathrm{R}$ & 60 & 46 & 101 & 11.7 & 1.7 & - & 10 \\
\hline Paepke [24] & 2009 & $\mathrm{P}$ & 94 & - & 34 & 1.1 & 0 & - & 1 \\
\hline Petit [25] & 2009 & $\mathrm{P}$ & 1001 & - & 20 & 1.4 & 1 & 35.8 & 9 \\
\hline Sakamoto [26] & 2009 & $\mathrm{R}$ & 89 & 50 & 52 & 0 & 0 & 22 & 18 \\
\hline Kim [27] & 2010 & $\mathrm{R}$ & 152 & 42 & 60 & 2 & 1.3 & 22.6 & 8 \\
\hline Boneti [28] & 2011 & $\mathrm{R}$ & 265 & 51 & 25 & 2.5 & 0 & 7.1 & - \\
\hline Alcantara [29] & 2011 & $\mathrm{R}$ & 157 & 44 & 10 & 0 & 0 & 21 & 3.3 \\
\hline Harness [30] & 2011 & $\mathrm{R}$ & 40 & 48 & 18 & 0 & 0 & 20 & 15 \\
\hline Jansen [31] & 2011 & $\mathrm{P}$ & 99 & - & 60 & 2.01 & 0 & 6 & 6.3 \\
\hline Maxwell [32] & 2011 & $\mathrm{R}$ & 53 & - & 22 & 1.4 & 1 & - & - \\
\hline Spear [33] & 2011 & $\mathrm{R}$ & 49 & 43 & 36 & 0 & 0 & 36 & 4.3 \\
\hline Petit [34] & 2012 & $\mathrm{R}$ & 934 & 47 & 50 & 8.5 & 3.7 & - & - \\
\hline Warren Peled [35] & 2012 & $\mathrm{R}$ & 412 & 47 & 28 & 1.9 & 0 & 42 & 3.5 \\
\hline Coopey [36] & 2013 & $\mathrm{R}$ & 315 & - & 22 & 2.6 & 0 & - & 1.7 \\
\hline Munhoz [37] & 2013 & $\mathrm{R}$ & 106 & - & 66 & 3.7 & 0 & - & 5 \\
\hline Sakurai [38] & 2013 & $\mathrm{R}$ & 788 & 51 & 78 & 8.2 & 3.7 & 0.6 & 0 \\
\hline Colwell [39] & 2014 & $\mathrm{R}$ & 222 & 46 & 26 & - & 0 & 12.4 & 4.4 \\
\hline Eisenberg [40] & 2014 & $\mathrm{R}$ & 208 & 50 & 33 & 0.5 & 0 & - & - \\
\hline Stanec $[41]$ & 2014 & $\mathrm{R}$ & 252 & 51 & 63 & 3.7 & 1.2 & - & 10.1 \\
\hline Sood [42] & 2014 & $\mathrm{R}$ & 76 & 47 & 30 & 7 & 1.3 & - & 3.4 \\
\hline Wang [43] & 2014 & $\mathrm{R}$ & 626 & - & 29 & 3 & 0 & 11.6 & 1 \\
\hline Poruk [44] & 2015 & $\mathrm{R}$ & 105 & 45 & 26 & 0.1 & 0 & - & - \\
\hline Shimo [45] & 2015 & $\mathrm{R}$ & 425 & 47 & 47 & 3.5 & 2.3 & - & 1.4 \\
\hline Yao [46] & 2015 & $\mathrm{R}$ & 99 & 41 & 33 & 3 & 0 & 8.3 & 1 \\
\hline Donovan [47] & 2016 & $\mathrm{R}$ & 144 & 47 & - & - & 0 & 21 & 11 \\
\hline Moo [48] & 2016 & $\mathrm{R}$ & 368 & 48 & 32 & 2.3 & 0.3 & - & - \\
\hline Orzalesi [49] & 2016 & $\mathrm{R}$ & 582 & 47 & 36 & 2.5 & - & 4.4 & 4.8 \\
\hline Brambullo [50] & 2017 & $\mathrm{R}$ & 30 & 46 & 60 & 0 & 0 & 20.8 & 20 \\
\hline Smith [51] & 2017 & $\mathrm{R}$ & 311 & 48 & 51 & 3.7 & 0 & - & 1.7 \\
\hline TOTAL & & & 8618 & 46.52 & 41.18 & 3.23 & 0.81 & 20.00 & 5.29 \\
\hline
\end{tabular}

NSM: Nipple sparing mastectomy; NAC: Nipple areoala-complex; LR: Local recurrence; R NAC: Recurrence at the NAC; R: Retrospective; P: Prospective. 
Table 2. Study characteristics with histologic tumor type, positive lymph node.

(a)

\begin{tabular}{|c|c|c|c|c|c|c|c|}
\hline \multirow[b]{2}{*}{ Authors } & \multirow[b]{2}{*}{ NSM } & \multirow{2}{*}{$\begin{array}{c}\text { Tumor size } \\
\mathbf{c m}\end{array}$} & \multicolumn{2}{|c|}{ Histologic tumor type } & \multirow{2}{*}{$\begin{array}{c}\text { Positive } \\
\text { Lymph } \\
\text { Nodes \% }\end{array}$} & \multirow[b]{2}{*}{ LR \% } & \multirow{2}{*}{$\begin{array}{c}\text { R.NAC } \\
\quad \%\end{array}$} \\
\hline & & & $\begin{array}{c}\text { Carcinoma in } \\
\text { situ \% }\end{array}$ & $\begin{array}{c}\text { invasive } \\
\text { carcinoma \% }\end{array}$ & & & \\
\hline Denewer [16] & 41 & & 5 & 95 & - & 0 & 0 \\
\hline Benediktsson [17] & 202 & & 14 & 86 & 40 & 24 & 4 \\
\hline Crowe [18] & 61 & & 25 & 75 & - & 3 & 0 \\
\hline Regolos [19] & 84 & & 14 & 86 & - & 0 & 0 \\
\hline Voltura [20] & 34 & 2.8 & 29 & 71 & 29 & 5.9 & 0 \\
\hline Wijayanayagan [21] & 35 & & 31 & 69 & - & 0 & 6.9 \\
\hline Garwood [22] & 99 & & 30 & 70 & & 0.6 & 0 \\
\hline Gerber [23] & 60 & & 18 & 82 & 53 & 11.7 & 1.7 \\
\hline Paepke [24] & 94 & & - & - & - & 1.1 & 0 \\
\hline Petit [25] & 1001 & & - & - & 38 & 1.4 & 1 \\
\hline Sakamoto [26] & 89 & & 10 & 90 & 37 & 0 & 0 \\
\hline Kim [27] & 152 & & 2 & 98 & - & 2 & 1.3 \\
\hline Boneti [28] & 265 & $1.9 \pm 1.6$ & 29 & 71 & 31 & 2.5 & 0 \\
\hline Alcantara [29] & 157 & & 47 & 53 & - & 0 & 0 \\
\hline Harness [30] & 40 & 2.5 & 37 & 63 & - & 0 & 0 \\
\hline Jansen [31] & 99 & & 35 & 65 & 24 & 2 & 0 \\
\hline Maxwell [32] & 53 & & 49 & 51 & 5 & 1.4 & 1 \\
\hline Spear [33] & 49 & & 8 & 92 & 55 & 0 & 0 \\
\hline Petit [34] & 934 & & 17 & 83 & - & 8.5 & 3.7 \\
\hline Warren Peled [35] & 412 & & 27 & 73 & - & 1.9 & 0 \\
\hline Coopey [36] & 315 & & 28 & 72 & 14 & 2.6 & 0 \\
\hline Munhoz [37] & 106 & & - & - & - & 3.7 & 0 \\
\hline Sakurai [38] & 788 & 2.5 & 3 & 97 & - & 8.2 & 3.7 \\
\hline Colwell [39] & 222 & & - & - & - & - & 0 \\
\hline Eisenberg [40] & 208 & & 28 & 72 & 26 & 0.5 & 0 \\
\hline Stanec $[41]$ & 252 & 1.8 & - & - & - & 3.7 & 1.2 \\
\hline Sood [42] & 76 & 2.1 & 32 & 68 & - & 7 & 1.3 \\
\hline Wang [43] & 626 & & 28 & 72 & - & 3 & 0 \\
\hline Poruk [44] & 105 & & - & - & - & 0.1 & 0 \\
\hline Shimo [45] & 425 & 1.6 & 23 & 77 & 26 & 3.5 & 2.3 \\
\hline Yao [46] & 99 & & - & - & - & 3 & 0 \\
\hline Donovan [47] & 144 & & - & - & - & - & 0 \\
\hline Moo [48] & 368 & 1.4 & 29 & 71 & - & 2.3 & 0.3 \\
\hline Orzalesi [49] & 582 & & - & - & - & 2.5 & - \\
\hline Brambullo [50] & 30 & & 27 & 73 & 63 & 0 & 0 \\
\hline Smith [51] & 311 & 1.5 & 23 & 77 & - & 3.7 & 0 \\
\hline TOTAL & 8618 & & & & & & \\
\hline
\end{tabular}

NSM: Nipple sparing mastectomy; NAC: Nipple areoala-complex; LR: Local recurrence; R NAC: Recurrence at the NAC. 
(b)

\begin{tabular}{cccccc}
\hline & & R.NAC \% & RL \% & $\begin{array}{c}\text { Overall } \\
\text { complication \% }\end{array}$ & $\begin{array}{c}\text { NECROSIS } \\
\text { NAC \% }\end{array}$ \\
\hline \multirow{2}{*}{ Mean Age year } & Pearson Correlation & 0.197 & 0.471 & -0.377 & 0.347 \\
& Sig. (Bilateral) & 0.336 & 0.018 & 0.166 & 0.113 \\
Mean & Pearson Correlation & $0.659 *$ & 0.817 & -0.364 & 0.222 \\
follow-month & Sig. (Bilateral) & $<0.001$ & $<0.001$ & 0,165 & 0.266 \\
\hline
\end{tabular}

46.52 years old.

Mean follow-up ranged from 8 months to 156 months with an average of 41.18 months.

The stage of the tumor ranged from stage 0 to III.

34 studies reported local recurrence rates. This rate varied between 0 and $24 \%$ with an average of $3.23 \%$.

35 studies reported recurrence at the NAC, the rate varied from 0 to $6.9 \%$ with an average rate of $0.81 \%$.

19 studies showed the rate of complications and 29 showed the nipple necrosis rates.

The complication rate ranged from $0.6 \%$ to $42 \%$ with an average of $20 \%$. NAC necrosis rate was from 0 to $20 \%$ with an average of $5.9 \%$.

The majority of studies were carried out after 2011, a subgroup analysis was performed by examining the average rates of complications and necrosis of the NAC before and after 2011. Prior to 2011, the total complication rates were found in 5 studies with an average of $29.76 \%$ and NAC necrosis rate of $6.66 \%$.

After 2011, the average rate of total complications was available for 13 studies, being at $16.24 \%$. Data on nipple necrosis for this period were available in 18 studies with an average rate of $5.43 \%$.

27 studies have provided information on histological types, with a predominance of invasive carcinomas, which represent $53 \%$ to $98 \%$.

13 studies included patients with lymph node involvement, with rates ranging from $5 \%$ to $63 \%$.

Under study group including tumor stages: Table 3.

11 studies reported information on the stages of the tumor with an average of $28 \%$ of tumors in stage $0.39 .4 \%$ in stage I, $17 \%$ in stage II and $4.91 \%$ in stage III.

The local recurrence was 1.4\%: for Petit [25] and Maxwell [32] which included only stage I and II, for authors which included stages II and III, it was $2 \%$ for Kim and Jansen [27] [31] and 3.7\% for Stanec [41].

Sub-group including radiotherapy rates: Table 4.

10 studies reported information on radiotherapy rates, notably the large series published by JY Petit [34] who studied a new protocol consisting of carrying out nipple-sparing mastectomies with associated intra-operative radiotherapy in 934 patients. For other studies, radiotherapy rates varied from $1 \%$ to $89.7 \%$, with an average rate of $23.4 \%$. The average rate of local recurrence was $4.75 \%$ and recurrence at the NAC is $0.73 \%$. The average rate of necrosis was $5.6 \%$ for this group 
Table 3. Sub group study including stages of tumor.

(a)

\begin{tabular}{lccccccc}
\hline \multicolumn{1}{c}{ Authors } & NSM & S0 \% & S1 \% & S2 \% & S3 \% & RL \% & R NAC \% \\
\hline Petit [25] & 1001 & 18 & 82 & 0 & 0 & 1.4 & 1 \\
Kim [27] & 152 & 12 & 46 & 36 & 5 & 2 & 1.3 \\
Alcantara [29] & 157 & 59 & 31 & 9 & 1 & 0 & 0 \\
Harness [30] & 99 & 35 & 28 & 15 & 2 & 0 & 0 \\
Jansen [31] & 99 & 35 & 28 & 26 & 10 & 2 & 0 \\
Maxwell [32] & 53 & 49 & 51 & 0 & 0 & 1.4 & 1 \\
Warren Peled [35] & 412 & 17 & 21 & 15 & 7 & 1.9 & 0 \\
Stanec [41] & 252 & 17 & 31 & 30 & 9 & 3.7 & 1.2 \\
Wang [43] & 626 & 16 & 20 & 17 & 8 & 3 & 0 \\
Moo [48] & 368 & 25 & 45 & 23 & 5 & 2.3 & 0.3 \\
Smith [51] & 311 & 25 & 51 & 17 & 7 & 3.7 & 0 \\
TOTAL & 3530 & $\mathbf{2 8}$ & $\mathbf{3 9 . 4 5}$ & 17.09 & 4.91 & 1.94 & 0.43 \\
\hline
\end{tabular}

S: Stage.

(b)

\begin{tabular}{cccccc}
\hline & & S0 \% & S1 \% & S2 \% & S3 \% \\
\hline RL\% & $\begin{array}{c}\text { Pearson } \\
\text { Correlation } \\
\text { Sig. (Unilateral) }\end{array}$ & $0.630^{*}$ & 0.015 & 0.455 & $\mathbf{0 . 7 2 5}$ \\
& $\begin{array}{c}\text { Pearson } \\
\text { PHSP\% }\end{array}$ & $\mathbf{0 . 2 8 4}$ & $\mathbf{0 . 5 3 5 ^ { * }}$ & 0.120 & $\mathbf{0 . 0 0 6}$ \\
& $\begin{array}{c}\text { Correlation } \\
\text { Sig. (Unilateral) }\end{array}$ & $\mathbf{0 . 1 9 8}$ & $\mathbf{0 . 0 4 5}$ & 0.2362 & 0.245 \\
\hline
\end{tabular}

of studies.

Sub-group study including the types of breast reconstruction: Table 5 .

14 studies reported information for the type of breast reconstruction procedures totalling 2441 with $29.22 \%$ of immediate breast reconstruction, $45.84 \%$ received follow-up expander prosthesis and $25.37 \%$ autologous reconstruction.

Authors who used expanders (De Alcantara [29], Spear [33], Warren Peled [35], Wang [43], Yao [46], Donovan [47]) had average rates of complications and necrosis of the NAC at $23.3 \%$ and $4.01 \%$ respectively.

Authors who used IBR (Regulus [19], Colwell [39], Sood [42], Brambullo [50] Smith [51]) reported an average rate of necrosis of the NAC of 5.9\%.

\section{Discussion}

The current literature review was conducted to provide an overview of the current data available for the nipple-sparing mastectomy in breast cancer treatment and to evaluate the safety of this procedure.

The main constraint found is the oncological safety of this technique with the 
Table 4. Sub-group study including radiotherapy rates.

(a)

\begin{tabular}{|c|c|c|c|c|c|}
\hline Authors & NSM & RTH \% & RL \% & R NAC \% & $\begin{array}{c}\text { NAC } \\
\text { NECROSIS } \\
\%\end{array}$ \\
\hline Benediktsson [17] 2008 & 202 & 22 & 24 & 4 & 8 \\
\hline Voltura [20] 2008 & 34 & 15 & 5.9 & 0 & - \\
\hline Gerber [23] 2009 & 60 & 29 & 11.7 & 1.7 & 10 \\
\hline Paepke [24] 2009 & 94 & 1 & 1.1 & 0 & 1 \\
\hline Sakamoto [26] 2009 & 89 & 30 & 0 & 0 & 18 \\
\hline Kim [27] 2010 & 152 & 5 & 2 & 1.3 & 8 \\
\hline Boneti [28] 2011 & 265 & 8 & 2.5 & 0 & - \\
\hline Jansen [31] 2011 & 99 & 16 & 2.01 & 0 & 6.3 \\
\hline Petit [34] 2012 & 934 & 100 Per-operative & 8.5 & 3.7 & - \\
\hline Warren peled [35] 2012 & 412 & 28 & 1.9 & 0 & 3.5 \\
\hline Coopey [36] 2013 & 315 & 7 & 2.6 & 0 & 1.7 \\
\hline Munhoz [37] 2013 & 106 & 9 & 3.7 & 0 & 5 \\
\hline Colwell [39] 2014 & 222 & 16 & - & 0 & 4.4 \\
\hline Sood [42] 2014 & 76 & 28 & 7 & 1.3 & 3.4 \\
\hline Wang [43] 2014 & 626 & 13 & 3 & 0 & 1 \\
\hline Poruk [44] 2015 & 105 & 90 & 0.1 & 0 & - \\
\hline Shimo [45] 2015 & 425 & 6 & 3.5 & 2.3 & 1.4 \\
\hline Donovan [47] 2016 & 144 & 13 & - & 0 & 11 \\
\hline Moo [48] 2016 & 368 & 14 & 2.3 & 0.3 & - \\
\hline Smith [51] 2017 & 311 & 18 & 3.7 & 0 & 1.7 \\
\hline TOTAL & 5039 & 23.40 & 4.75 & 0.73 & 5.62 \\
\hline
\end{tabular}

(b)

\begin{tabular}{ccccc}
\hline & & RL \% & R NAC \% & $\begin{array}{c}\text { NAC } \\
\text { NECROSIS \% }\end{array}$ \\
\hline \multirow{2}{*}{ RTH\% } & Pearson Correlation & 0.096 & 0.362 & 0.482 \\
& significance & 0.704 & 0.117 & 0.069 \\
\hline
\end{tabular}

possibility of leaving residual disease in the skin envelope which can cause delayed local recurrences.

The second constraint is the risk of complications, particularly necrosis of the NAC. The available studies are heterogeneous, with differences in patient selection criteria, treatment and monitoring period protocols. The results are, therefore, difficult to compare across studies. 
Table 5. Sub-group study including the types of breast reconstruction.

(a)

\begin{tabular}{|c|c|c|c|c|c|c|}
\hline Authors & NSM & IBR \% & $\begin{array}{c}\text { EXP/ } \\
\text { PROSTHESIS } \\
\%\end{array}$ & $\begin{array}{c}\text { AUTOLOGOUS } \\
\%\end{array}$ & $\begin{array}{c}\text { Overall } \\
\text { complication \% }\end{array}$ & $\begin{array}{c}\text { NECROSIS } \\
\text { NAC \% }\end{array}$ \\
\hline Denewer [16] 2007 & 41 & 0 & 0 & 100 & 26.4 & 2.4 \\
\hline Regolo [19] 2008 & 84 & 75.7 & 24.28 & 0 & - & 0 \\
\hline Gerber [23] 2009 & 60 & 0 & 0 & 100 & - & 10 \\
\hline Kim [27] 2010 & 152 & 0 & 0 & 100 & 22.6 & 8 \\
\hline Alcantara [29] 2011 & 157 & 0 & 99.7 & 0.3 & 21 & 3.3 \\
\hline Spear [33] 2011 & 49 & 8 & 86 & 6 & 36 & 4.3 \\
\hline Warren Peled [35] 2012 & 412 & 4.6 & 81.1 & 14.3 & 42 & 3.5 \\
\hline Colwell [39] 2014 & 222 & 59.3 & 38.4 & 11 & 12.4 & 4.4 \\
\hline Sood [42] 2014 & 76 & 94 & 6 & 0 & - & 3.4 \\
\hline Wang [43] 2014 & 626 & 0.3 & 89 & 10.2 & 11.6 & 1 \\
\hline Yao [46] 2015 & 99 & 0 & 94.5 & 5.5 & 8.3 & 1 \\
\hline Donovan [47] 2016 & 144 & 29 & 64 & 5.1 & 21 & 11 \\
\hline Brambullo [50] 2017 & 30 & 73.3 & 26.7 & 0 & 20.8 & 20 \\
\hline Smith [51] 2017 & 311 & 65 & 32.2 & 2.8 & - & 1.7 \\
\hline TOTAL & 2441 & 29.22 & 45.84 & 25.37 & 22.21 & 5.28 \\
\hline
\end{tabular}

IBR: Immediate breast reconstruction; EXP: Expander.

(b)

\begin{tabular}{lcccc}
\hline & & IBR \% & EXP/PROSTHESES \% & AUTOLOGOUS \% \\
\hline \multirow{2}{*}{ CCOMPLICATIONS\% } & Correlation coefficient & -0.060 & -0.311 & 0.409 \\
& Sig. $(\mathrm{P}=$ unilateral $)$ & 0.435 & 0.191 & 0.121 \\
\hline
\end{tabular}

\subsection{Local Recurrence}

Local recurrence after nipple-sparing mastectomy can occur in two ways.

Firstly, glandular tissue could be left behind in the NAC [52], or on the skin pouch in areas difficult to access on the periphery of the gland, especially with incisions in the crease under the breast [53]. Histological studies after conventional mastectomy reported residual glandular tissue in 5\% of all biopsies, indicating that radical surgery does not guarantee complete removal [54]. In mastectomies with the preservation of the skin pouch, in patients with invasive breast cancer, the breast tissue was found, in 59.5\%, to have cases of residual disease in $9.5 \%$ of patients [10].

Secondly, where the NAC may be the seat of the residual occult disease [13], in $1.2 \%$ to $5.9 \%$ of cases, it is often a ductal carcinoma in situ [20] [21] [33] [55].

The residual glandular parenchyma and occult disease could lead to high rates of local recurrence after nipple-sparing mastectomy. However, this study found 
a low rate of local recurrence of $3.23 \%$, and a low recurrence rate at the NAC to $0.81 \%$. These rates are comparable to those found after conventional mastectomy [56] [57].

For Munhoz and Stanec [37] [38] [39] [40] [41], after a follow-up of 66 and 63 months, there was a local recurrence rate of $3.7 \%$ and the relapse rate at the NAC of $0 \%$ and $1.2 \%$ respectively.

De la Cruz [58], in a meta-analysis of 9 studies, found a local recurrence rate of 5.4\% after nipple-sparing mastectomy, over a 36-month follow-up.

3 studies have found no cases of recurrence in the NAC [16] [18] [19] [20] [22] [24] [26] [28] [29] [30] [31] [33] [35] [36] [37] [39] [40] [43] [44] [46] [47] [50] [51] with a mean follow-up ranging from 7.9 months 65.6 months.

The highest rates of local recurrence after nipple-sparing mastectomy are 11.7\% (Geaber [23]) and 24\% (Benediktsonn [17]). These figures can be explained by the longer follow-up periods. But there are many biases in these studies. In fact, there were no exclusion criteria, as $40 \%$ of tumors were $\mathrm{N}$ positive for Benediktsonn [17] and 53\% N positive for Gerber [23].

The criteria for nipple sparing mastectomies are not always well defined and vary in studies between institutions.

The procedure has not been performed in patients with clinical involvement of the NAC in case of inflammatory cancer or in case of retro-areal central tumors.

The nipple-sparing mastectomy was performed for stage 0 to III and studies included 11 stages of the tumor, but we have not noticed significantly higher rates of local recurrence or relapse at the NAC in studies including stages II and III.

The tumor size is a parameter that has been used to select patients. In studies including data on tumor size, the largest recorded average tumor size was $3.4 \pm$ $2.2 \mathrm{~cm}$ with a local recurrence rate of $10.3 \%$ over an 18-month follow-up [59].

More recently, Leclere [60] reported a local recurrence rate of 5.3\%, including tumors of more than $3 \mathrm{~cm}$.

Currently available data seem to support the success of the nipple-sparing mastectomy in the case of larger tumors, although longer-term follow-up studies with larger populations are needed to ensure the safety of the procedure.

Another selection parameter that has been suggested is a tumor-nipple distance of $>2 \mathrm{~cm}$. Currently, a retro-areal overlap is required for histological analysis to verify that NAC margins are healthy [61]. This overlap can help indicate an occult disease. This ranged from $5.6 \%$ to $31 \%$ [29]. Aleprovich described retro-areal biopsies as specific and of low sensitivity [62].

A recent study by Chattopadhyay [61] found a local recurrence rate of $0 \%$ after 28 months in patients with a mean tumor-nipple distance of $3.8 \mathrm{~cm}$.

This low rate was confirmed by Fortunato [59] who found a local recurrence rate of less than $1 \%$ after 26 months follow-up, when tumor-nipple distance was only $1 \mathrm{~cm}$ in $65 \%$ of cases. 
Optimal tumor-nipple distance is not yet well defined, and the number of procedures in the studies is small and requires validation by larger studies.

To evaluate this distance preoperatively, clinical examination and imaging techniques are the best way to select patients; Moon [63] found that IBR had a sensitivity of $93.8 \%$ and a specificity of $85.7 \%$ for predicting the affected NAC.

Lymph node status was not found as a factor affecting the nipple, but there was no consensus to retain it as selection criteria for nipple-sparing mastectomies [25] [33].

Regarding the molecular parameters, the nipple-sparing mastectomy is not recommended in patients with vascular emboli, negative hormone receptors or HER2+, as with these patients local recurrences are more related to these molecular factors than to the preservation of the NAC [20].

Based on these selection criteria, the nipple-sparing mastectomy seems to be a safe procedure from an oncological perspective, in patients with breast cancer. Although the risk of occult nipple disease is real, local recurrence rates are low. The factors that expose significantly to the risk of local recurrence, are the tumor size and the stage $>$ II $(\mathrm{p}<0.05)$.

\subsection{Complications}

Several studies have evaluated complication rates and necrosis of the NAC after nipple-sparing mastectomy.

Total complications ranged from $0.6 \%$ to $42 \%$ with an average of $20 \%$, and necrosis rates of the NAC from $0 \%$ to $20 \%$, with an average of $5.29 \%$.

These rates are low despite the necrotic risk of the procedure.

The complication rates and necrosis are lower after 2011, with a significant difference of $\mathrm{p}<0.05$, which reflects a good control of the surgical technique and the careful selection of patients.

It is likely that NAC necrosis is influenced by factors related to the patient and the surgical technique; authors have found obesity as a risk factor for necrosis [39]. Komorowski [64] showed that patient age of over 45 years is a risk factor. Garwood [22] found that smoking is a factor associated with necrosis of the NAC. We have, however, not found age to be a factor associated with necrosis of the NAC.

Others have concluded that the type of incision has a negative impact, and this is the case of peri areolar incisions of over $30 \%$ of the areolar circumference [65].

Crowe suggests that the lateral incision is best to keep the blood supply to the NAC [66], but from the literature no incision seems to be ideal.

The preservation of subcutaneous fat also allows the preservation of the subdermal vascular network [67], where a thickness of $5 \mathrm{~mm}$ has been recommended to avoid necrosis of the NAC [17] [37] [65].

Radiation therapy has been considered by some as a contraindication of the nipple-sparing mastectomy, due to its overall complications [18] [68]. However, radiation therapy is not associated with a high risk of necrosis of the NAC [69]. 
Petit et al. [25], whilst retaining $5 \mathrm{~mm}$ of glandular tissue under the NAC, administered an intraoperative dose of radiotherapy to reduce the risk of local recurrence. However, the results are comparable to those not using this technique.

In the 16 studies which included patients who underwent radiotherapy, we have not seen a significant increase in NAC necrosis rates compared to studies that did not include radiotherapy.

Studies including types of reconstruction (Table 4) showed a slight and nonsignificant increase in complication rates in cases of immediate breast reconstruction. This can be explained by a careful selection of patients and the use of acellular dermal matrices. Other studies have reached the same conclusions [70]. Garwood [22] found that immediate breast reconstruction by prosthesis could increase the rate of necrosis and therefore the use of expanders may reduce this risk.

We found that there is no ideal protocol, the decision is based on a preoperative and preoperative assessment of the subcutaneous thickness of the NAC [9] [53].

\section{Conclusions}

Despite the heterogeneity of the majority of retrospective studies, variable inclusion criteria and different methodologies, this review of the literature has shown that the nipple-sparing mastectomy is a reliable technique, and is oncologically safe, in patients with breast cancer.

These results have been achieved through a careful selection of patients which is based on clinical and imaging procedures. However, it is necessary to carry out further studies and especially to perform tests to determine further recommendations based on a high level of evidence.

\section{Conflicts of Interest}

The authors declare no conflicts of interest regarding the publication of this paper.

\section{References}

[1] Morrow, M., Bucci, C. and Rademaker, A. (1998) Medical Contraindications Are Not a Major Factor in the Underutilization of Breast Conserving Therapy. Journal of the American College of Surgeons, 186, 269-274. https://doi.org/10.1016/S1072-7515(97)00153-1

[2] Baum, M., Budzar, A.U., Cuzick, J., Forbes, J., Houghton, J.H., Klijn, J.G., et al. (2002) Anastrozole Alone or in Combination with Tamoxifen versus Tamoxifen Alone for Adjuvant Treatment of Postmenopausal Women with Early Breast Cancer: First Results of the ATAC Randomized Trial. The Lancet, 359, 2131-2139. https://doi.org/10.1016/S0140-6736(02)09088-8

[3] Wellisch, D.K., Schain, W.S., Noone, R.B. and Little, J.W. (1987) The Contribution of Psychological Addition Nipple in Breast Reconstruction. Plastic and Reconstruc- 
tive Surgery, 80, 699-704.

https://doi.org/10.1097/00006534-198711000-00007

[4] Didier, F., Radice, D., Gandini, S., Bedolis, R., Rotmensz, N., Maldifassi, A., et al. (2009) Does Nipple Preservation in Mastectomy Improve Satisfaction with Cosmetic Results, Psychological Adjustment, Body Frame and Sexuality? Breast Cancer Research and Treatment, 118, 623-633. https://doi.org/10.1007/s10549-008-0238-4

[5] Freeman, B.S. (1962) Subcutaneous Mastectomy for Benign Breast Lesions with Immediate or Delayed Prosthetic Replacement. Plastic and Reconstructive Surgery, 30, 676-682. https://doi.org/10.1097/00006534-196212000-00008

[6] Boughey, J.C. and Mc Laughlin, S.A. (2015) Breast Surgery in 2015: Advances in Recent Years. Annals of Surgical Oncology, 22, 3157-3160. https://doi.org/10.1245/s10434-015-4752-4

[7] Rebbeck, T.R., Friebel, T., Lynch, H.T., et al. (2004) Bilateral Prophylactic Mastectomy Reduces Breast Cancer Risk in BRCA1 and BRCA2 Mutation Carriers: The PROSE Study Group. Journal of Clinical Oncology, 22, 1055-1062. https://doi.org/10.1200/JCO.2004.04.188

[8] Chung, A.P. and Sacchini, V. (2010) Nipple-Sparing Mastectomy: Where Are We Now? Surgical Oncology, 19, 114. https://doi.org/10.1016/j.suronc.2009.11.004

[9] Beer, G.M., Varga, Z., Budi, S., Seifert, B. and Meyer, V.E. (2002) Impact of the Superficial Fascia and Its Relevance in Skin-Sparing Mastectomy. Cancer, 94, 1619-1625. https://doi.org/10.1002/cncr.10429

[10] Torresan, R.Z., dos Santos, C.C., Okamura, H. and Alvarenga (2005) Evaluation of Residual Glandular Tissue-Sparing Mastectomies After-Skin. Annals of Surgical Oncology, 12, 1037-1044. https://doi.org/10.1245/ASO.2005.11.027

[11] Sacchini, V., Pinotti, J.A., Barros, A.C., et al. (2006) Nipple-Sparing Mastectomy for Breast Cancer and Risk Reduction: Oncologic or Technical Problem? Journal of the American College of Surgeons, 203, 704-714. https://doi.org/10.1016/j.jamcollsurg.2006.07.015

[12] Cao, D., Tsangaris, T.N., Kouprina, N., et al. (2008) The Margin of the Superficial Skin-Sparing Mastectomy for Breast Carcinoma: Factors Predicting Involvement and Efficacy of Additional Sampling Margin. Annals of Surgical Oncology, 15, 1330-1340. https://doi.org/10.1245/s10434-007-9795-8

[13] Gerber, B., Krause, A., Reimer, T., et al. (2003) Skin-Sparing Mastectomy with Preservation of the Nipple-Areola Complex and Autologous Reconstruction Is an Oncologically Safe Procedure. Annals of Surgery, 238, 120-127.

https://doi.org/10.1097/01.SLA.0000077922.38307.cd

[14] Babiera, G. and Simmons, R. (2010) Nipple-Areolar Complex-Sparing Mastectomy: Feasibility, Select the Patient, and Technical. Annals of Surgical Oncology, 17, S245-S248. https://doi.org/10.1245/s10434-010-1256-0

[15] Wagner, J.L., Fearmonti, R., Hunt, K.K., et al. (2012) Prospective Assessment of the Nipple-Areola Complex-Sparing Mastectomy for Risk Reduction and for Early-Stage Breast Cancer. Annals of Surgical Oncology, 19, 1137-1144. https://doi.org/10.1245/s10434-011-2099-Z

[16] Denewer, A. and Farouk, O. (2007) Can Nipple-Sparing Mastectomy and Immediate Breast Reconstruction with Modified Extended Latissimus Dorsi Muscular Flap Improve the Cosmetic and Functional Outcome among Patients with Breast Carcinoma? World Journal of Surgery, 31, 1169-1177.

https://doi.org/10.1007/s00268-007-9046-y 
[17] Benediktsson, K.P. and Perbeck, L. (2008) Survival in Breast Cancer After-NippleSparing Mastectomy and Immediate Reconstruction Subcutaneous Implants with a Prospective Trial with 13 Years Median Follow-Up in 216 Patients. European Journal of Surgical Oncology, 34, 143-148. https://doi.org/10.1016/j.ejso.2007.06.010

[18] Crowe, J.P., Patrick, R.J., Yetman, R.J., et al. (2008) Nipple-Sparing Mastectomy Update: One Hundred Forty-Nine Procedures and Clinical Outcomes. Archives of Surgery, 143, 1106-1110. https://doi.org/10.1001/archsurg.143.11.1106

[19] Regulus, L., Ballardini, B., Gallarotti, E., et al. (2008) Nipple Sparing Mastectomy: An Innovative Skin Incision for an Alternative Approach. Breast, 17, 8-11. https://doi.org/10.1016/j.breast.2007.07.040

[20] Voltura, A.M., Tsangaris, T.N., Rosson, G.D., et al. (2008) Nipple-Sparing Mastectomy: Critical Assessment of 51 Procedures and Implications for the Selection Criteria. Annals of Surgical Oncology, 15, 3396-3401. https://doi.org/10.1245/s10434-008-0102-0

[21] Wijayanayagam, A., Kumar, A.S., Foster, R.D., et al. (2008) Optimizing the Total Skin-Sparing Mastectomy. Archives of Surgery, 143, 38-45.

https://doi.org/10.1001/archsurg.143.1.38

[22] Garwood, E.R., Moore, D., Ewing, C., et al. (2009) Total Skin-Sparing Mastectomy: Complications and Local Recurrence Rates in 2 Cohorts of Patients. Annals of Sur gery, 249, 26-32. https://doi.org/10.1097/SLA.0b013e31818e41a7

[23] Gerber, B., Krause, A., Dieterich, M., et al. (2009) The Oncological Safety of Skin Sparing Mastectomy with Preservation of the Nipple-Areola Complex and Autologous Reconstruction: An Extended Follow-Up Study. Annals of Surgery, 249, 461-468. https://doi.org/10.1097/SLA.0b013e31819a044f

[24] Paepke, S., Schmid, R., Fleckner, S., et al. (2009) Subcutaneous Mastectomy with Preservation of the nipple-Areola Skin: Broadening the Indications. Annals of Surgery, 250, 288-292. https://doi.org/10.1097/SLA.0b013e3181b0c7d8

[25] Petit, J.Y., Veronesi, U., Orecchia, R., et al. (2009) Nipple Sparing Mastectomy with Nipple Areola Intraoperative Radiotherapy: One Thousand and One Box of a Five Years Experience at the European Institute of Oncology of Milan (EIO). Breast Cancer Research and Treatment, 117, 333-338. https://doi.org/10.1007/s10549-008-0304-y

[26] Sakamoto, N., Fukuma, E., Higa, K., et al. (2009) Early Results of an Endoscopic Nipple-Sparing Mastectomy for Breast Cancer. Annals of Surgical Oncology, 16, 3406-3413. https://doi.org/10.1245/s10434-009-0661-8

[27] Kim, H.J., Park, E.H., Lim, W.S., et al. (2010) Nipple-Sparing Mastectomy Areola Skin with Immediate Transverse Rectus Abdominis Musculocutaneous Flap Reconstruction Is an Oncologically Safe Procedure: A Single Center Study. Annals of Surgery, 251, 493-498. https://doi.org/10.1097/SLA.0b013e3181c5dc4e

[28] Boneti, C., Yuen, J., Santiago, C., et al. (2011) Oncologic Safety of Nipple SkinSparing Total Gold Skin-Sparing Mastectomy with Immediate Reconstruction. Journal of the American College of Surgeons, 212, 686-693.

https://doi.org/10.1016/j.jamcollsurg.2010.12.039

[29] Alcantara Filho, P., Capko, D., Barry, J.M., et al. (2011) Nipple-Sparing Mastectomy for Breast Cancer and Risk-Reducing Surgery: The Memorial Sloan Kettering Cancer Center Experience. Annals of Surgical Oncology, 18, 3117-3122. https://doi.org/10.1245/s10434-011-1974-y

[30] Harness, J.K., Vetter, T.S. and Salibian, A.H. (2011) Areola and Nipple-AreolaSparing Mastectomy for Breast Cancer Treatment and Risk Reduction: Report of 
Initial Experience Year in a Community Hospital Setting. Annals of Surgical Oncology, 18, 917-922. https://doi.org/10.1245/s10434-010-1365-9

[31] Jensen, J.A., Orringer, J.S. and Giuliano, A.E. (2011) Nipple-Sparing Mastectomy in 99 Patients with a Mean Follow-Up of 5 Years. Annals of Surgical Oncology, 18, 1665-1670. https://doi.org/10.1245/s10434-010-1475-4

[32] Maxwell, G.P., Storm-Dickerson, T., Whitworth, P., Rubano, C. and Gabriel, A. (2011) Advances in Nipple-Sparing Mastectomy: Oncological Safety and Incision Selection. Aesthetic Surgery Journal, 31, 310-319.

https://doi.org/10.1177/1090820X11398111

[33] Spear, S.L., Willey, S.C., Feldman, E.D., et al. (2011) Nipple-Sparing Mastectomy for Prophylactic and Therapeutic Indications. Plastic and Reconstructive Surgery, 128, 1005-1014. https://doi.org/10.1097/PRS.0b013e31822b6456

[34] Petit, J.Y., Veronesi, U., Orecchia, R., Curigliano, G., Rey, P.C., Botteri, E., Rotmensz, N., Lohsiriwat, V., Cassilha Kneubil, M. and Rietjens, M. (2012) Risk Factors Associated with Recurrence After-Nipple-Sparing Mastectomy for and Invasive Intraepithelial Neoplasia. Annals of Oncology, 23, 2053-2058.

https://doi.org/10.1093/annonc/mdr566

[35] Warren Peled, A., Foster, R.D., Stover, A.C., et al. (2012) Outcomes After-Total Skin-Sparing Mastectomy and Immediate Reconstruction in 657 Breasts. Annals of Surgical Oncology, 19, 3402-3409. https://doi.org/10.1245/s10434-012-2362-y

[36] Coopey, S.B., Tang, R., Lei, L., et al. (2013) Increasing Admissibilité for NippleSparing Mastectomy. Annals of Surgical Oncology, 20, 3218-3222.

https://doi.org/10.1245/s10434-013-3152-x

[37] Munhoz, A.M., Aldrighi, C.M., Montag, E., et al. (2013) Clinical Outcomes Following Nipple-Areola-Sparing Mastectomy with Immediate Breast Implant-Based Reconstruction: A 12-Year Experience with an Analysis of Breast and Patient-Related Factors for Complications. Breast Cancer Research and Treatment, 140, 545-555. https://doi.org/10.1007/s10549-013-2634-7

[38] Sakurai, T., Zhang, N., Suzuma, T., et al. (2013) Long-Term Follow-Up of Nipple-Sparing Mastectomy without Radiotherapy: A Single Center Study at a Japanese Institution. Medical Oncology, 30, 481. https://doi.org/10.1007/s12032-013-0481-3

[39] Colwell, A.S., Tessler, O., Lin, A.M., et al. (2014) Breast Reconstruction Following Nipple-Sparing Mastectomy: Predictors of Complications, Reconstruction Outcomes, and 5-Year Trends. Plastic and Reconstructive Surgery, 133, 496-506. https://doi.org/10.1097/01.prs.0000438056.67375.75

[40] Eisenberg, R.E., Chan, J.S., Swistel, A.J., et al. (2014) Pathological Assessment of Nipple-Sparing Mastectomies with Emphasis on Occult Nipple Involvement: The Weill-Cornell Experience with 325 Cases. The Breast Journal, 20, 15-21.

https://doi.org/10.1111/tbj.12199

[41] Stanec, Z., Zic Budi, R.S., et al. (2014) Skin and Nipple-Areola Complex Sparing Mastectomy in Breast Cancer Patients: 15-Year Experience. Annals of Plastic Surgery, 73, 485-491. https://doi.org/10.1097/SAP.0b013e31827a30e6

[42] Sood, S., Elder, E. and French, J. (2015) Nipple-Sparing Mastectomy with Implant Reconstruction: The Westmead Experience. ANZ Journal of Surgery, 85, 363-367. https://doi.org/10.1111/ans.12641

[43] Wang, F., Peled, A.W., Garwood, E., et al. (2014) Total Skin-Sparing Mastectomy and Immediate Breast Reconstruction: An Evolution of Technical and Assessment of Outcomes. Annals of Surgical Oncology, 21, 3223-3230. https://doi.org/10.1245/s10434-014-3915-Z 
[44] Poruk, K.E., Ying, J., Chidester, J.R., et al. (2015) Breast Cancer Recurrence After-Nipple-Sparing Mastectomy: One Institution's Experience. The American Journal of Surgery, 209, 212-217. https://doi.org/10.1016/j.amjsurg.2014.04.001

[45] Shimo, A., Tsugawa, K., et al. (2016) Oncologic Outcomes and Technical Considerations of Nipple-Sparing Mastectomy in Breast Cancer: Experience of 425 Cases from a Single Institution. Breast Cancer, 23, 851-860.

https://doi.org/10.1007/s12282-015-0651-6

[46] Yao, K., Liederbach, E., Tang, R., et al. (2015) Nipple-Sparing Mastectomy in BRCA1/2 Mutation Carriers: An Interim Analysis and Review of the Literature. Annals of Surgical Oncology, 22, 370-376.

https://doi.org/10.1245/s10434-014-3883-3

[47] Donovan, C.A., Harit, A.P., Chung, A., Bao, J., Giuliano, A.E. and Amersi, F. (2016) Oncological and Surgical Outcomes After-Nipple-Sparing Mastectomy: Incisions Do Matter? Annals of Surgical Oncology, 23, 3226-3231.

https://doi.org/10.1245/s10434-016-5323-Z

[48] Moo, T.A., et al. (2016) Oncologic Outcomes after Nipple-Sparing Mastectomy. Annals of Surgical Oncology, 23, 3221-3225. https://doi.org/10.1245/s10434-016-5366-1

[49] Orzalesi, L., Casella, D., Santi, C., et al. (2016) Nipple Sparing Mastectomy: Surgical and Oncological Outcomes from a National Multicentric Registry with 913 Patients (1006 Boxes) over a Six Year Period. The Breast, 25, 75-81.

https://doi.org/10.1016/j.breast.2015.10.010

[50] Brambullo, T., Dalla Venezia, E., Martella, S., Vindigni, V., Bassetto, F., Gottardi, A., Lohsiriwat, V., Small, J.Y., Veronesi, P. and Rietjens, M. (2017) Conservative versus Mastectomy Nipple-Sparing Mastectomy: Preliminary Considerations of Oncological Safety on 30 Patients Not Receiving Send Intra-Operative Radiotherapy. Gland Surgery, 6, 654-658. https://doi.org/10.21037/gs.2017.07.17

[51] Smith, B.L., Tang, R., Rai, U., Plichta, J.K., Colwell, A.S., Gadd, M.A., Specht, M.C., Austen, W.G. and Coopey, S.B. (2017) Oncologic Safety of Nipple-Sparing Mastectomy in Women with Breast Cancer. Journal of the American College of Surgeons, 225, 361-365. https://doi.org/10.1016/j.jamcollsurg.2017.06.013

[52] Lohsiriwat, V., Martella, S. and Rietjens (2012) Paget's Disease as a Local Recurrence after-Nipple-Sparing Mastectomy: Clinical Presentation, Treatment, Outcome, and Risk Factor Analysis. Annals of Surgical Oncology, 19, 1850-1855. https://doi.org/10.1245/s10434-012-2226-5

[53] Colwell, A.S., Gadd, M., Smith, B.L. and Austen, W.G. (2010) An Approach to Inferolateral Nipple-Sparing Mastectomy. Annals of Plastic Surgery, 65, 140-143. https://doi.org/10.1097/SAP.0b013e3181c1fe77

[54] Barton, F.E., English, J.M., Kingsley, W.B., et al. (1991) Glandular Excision in the Total Glandular Mastectomy and Modified Radical Mastectomy: A Comparison. Plastic and Reconstructive Surgery, 88, 389-392. https://doi.org/10.1097/00006534-199109000-00001

[55] Chen, C.M., Disa, J.J., Sacchini, V., et al. (2009) Nipple-Sparing Mastectomy and Immediate Tissue Expander/Implant Breast Reconstruction. Plastic and Reconstructive Surgery, 124, 1772-1780. https://doi.org/10.1097/PRS.0b013e3181bd05fd

[56] Overgaard, M., Nielsen, H.M. and Overgaard, J. (2007) Is the Benefit of PostMastectomy Radiation Limited to Patients with Positive Nodes Oven or More, as Recommended in International Consensus Deferrals? A Subgroup Analysis of the DBCG 82 b \& c Randomized Trials. Radiotherapy and Oncology, 82, 247-253. https://doi.org/10.1016/j.radonc.2007.02.001 
[57] Veronesi, U., et al. (1995) Breast conservation Is a Safe Method in Patients with Small Cancer of the Breast. Long-Term Results of Three Randomized Trials on 1973 Patients. European Journal of Cancer, 31, 1574-1579. https://doi.org/10.1016/0959-8049(95)00271-J

[58] De La Cruz, L., Moody, A.M., Tappy, E.E., et al. (2015) Overall Survival, Disease-Free Survival, Local Recurrence, and Nipple-Areolar Recurrence in the Setting of Nipple-Sparing Mastectomy: A Meta-Analysis and Systematic Review. Annals of Surgical Oncology, 22, 3241-3249. https://doi.org/10.1245/s10434-015-4739-1

[59] Fortunato, L., Loreti, A. andrich, R., et al. (2013) When Mastectomy Is Needed: Is the Nipple-Sparing Procedure to New Standard with Very FEW Contraindications? Journal of Surgical Oncology, 108, 207-212. https://doi.org/10.1002/jso.23390

[60] Leclere, F.M., Panet-Spallina, J., Kolb, F., et al. (2014) Nipple-Sparing Mastectomy and Immediate Reconstruction in Ductal Carcinoid Noma in Situ: A Critical Assessment with 41 Patients. Aesthetic Plastic Surgery, 38, 338-343.

https://doi.org/10.1007/s00266-013-0236-8

[61] Chattopadhyay, D., Gupta, S., Jash, P.K., et al. (2014) Skin Sparing Mastectomy with Preservation of Nipple Areola Complex and Immediate Breast Reconstruction in Patients with Breast Cancer: A Prospective Single Center Study. Plastic Surgery International, 2014, Article ID: 589068. https://doi.org/10.1155/2014/589068

[62] Alperovich, M., Choi, M., Karp, N.S., et al. (2016) Nipple-Sparing Mastectomy and Sub-Areolar Biopsy: To Freeze or Not to Freeze? Evaluating the Role of Intraoperative Frozen Section Subareolar. The Breast Journal, 22, 18-23.

https://doi.org/10.1111/tbj.12517

[63] Moon, J.Y., Chang, Y.W., Lee, E.H., et al. (2013) Malignant Invasion of the Nipple-Areolar Complex of the Breast: Usefulness of Breast MRI. American Journal of Roentgenology, 201, 448-455. https://doi.org/10.2214/AJR.12.9186

[64] Komorowski, A.L., Zanini, V., The Regolo, A., Carolei, W.M. and Wysocki, A.C. (2006) Necrotic Complications after Nipple and Areola-Sparing Mastectomy. World Journal of Surgery, 30, 1410-1413.

https://doi.org/10.1007/s00268-005-0650-4

[65] Algaithy, Z.K., Petit, J.Y., Lohsiriwat, V., et al. (2012) Nipple Sparing Mastectomy: Can We Predict the Factors Predisposing to Necrosis? European Journal of Surgical Oncology, 38, 125-129. https://doi.org/10.1016/j.ejso.2011.10.007

[66] Crowe, J.P., Kim, J.A., Yetman, R., et al. (2004) Nipple-Sparing Mastectomy: Technical and Results of 54 Procedures. Archives of Surgery, 139, 148-150.

https://doi.org/10.1001/archsurg.139.2.148

[67] Stolier, A.J., Sullivan, S.K. and Dellacroce, F.J. (2008) Technical Considerations in Nipple-Sparing Mastectomy: 82 Consecutive Cases without Necrosis. Annals of Surgical Oncology, 15, 1341-1347. https://doi.org/10.1245/s10434-007-9753-5

[68] Blechman, K.M., Karp, N.S., Levovitz, C., et al. (2013) The Lateral Inframammary Fold Incision for Nipple-Sparing Mastectomy: Outcomes from over 50 Immediate Implant-Based Breast Reconstruction. The Breast Journal, 19, 31-40. https://doi.org/10.1111/tbj.12043

[69] Alperovich, M., Choi, M., Frey, J.D., et al. (2014) Nipple-Sparing Mastectomy in Patients with Prior Breast Radiation: Are Patients at Higher Risk for Reconstructive Complications? Plastic and Reconstructive Surgery, 134, 202-206. https://doi.org/10.1097/PRS.0000000000000321

[70] Gunnarsson, G.L., Børsen Koch, M., Wamberg, P., et al. (2014) How to Perform a NAC Sparing Mastectomy Using an ADM and an Implant. Gland Surgery, 3, 252-257. 


\section{Abbreviations}

NAC: Nipple areola complex.

NSM: Nipple sparing mastectomy.

LR: Local reccurence.

R.NAC: NAC reccurence.

S0: Stage 0.

S1: Stage 1.

S2: Stage 2.

S3: Stage 3.

S4: Stage 4.

RTH: Radiotherapy.

IBR: Immediate breast reconstruction.

EXP: Expander.

HER2: Human epidermal growth factor receptor 2.

MRI: Magnetic resonance imaging. 